\title{
Synthesis of Benzimidazoles Using Pomegranate Peel Powder as a Natural and Efficient Catalyst
}

\author{
Swati S. Ghodke ${ }^{1}$, Priya M. Khandare ${ }^{1}$, Rajita D. Ingle ${ }^{1}$, Sunil U. Tekale ${ }^{1}$, Rajendra P. Pawar ${ }^{1, *}$ \\ 1 Department of Chemistry, Deogiri College, Aurangabad, Maharashtra, India \\ * Correspondence: rppawar@yahoo.com;
}

Scopus Author ID 7003738785

Received: 6.12.2020; Revised: 7.01.2021; Accepted: 10.01.2021; Published: 19.01.2021

\begin{abstract}
In the present work, we report an efficient route for the synthesis of benzimidazole derivatives by the reaction of aromatic aldehydes and o-phenylenediamine at room temperature by using pomegranate peel powder (PGP) as a natural catalyst. The present method represents a green and valuable addition to the existing methods for the synthesis of benzimidazoles.
\end{abstract}

Keywords: aromatic aldehyde; o-phenylenediamine; natural catalyst; pomegranate peel.

(C) 2020 by the authors. This article is an open-access article distributed under the terms and conditions of the Creative Commons Attribution (CC BY) license (https://creativecommons.org/licenses/by/4.0/).

\section{Introduction}

Benzimidazole scaffold is a bicyclic compound, having an imidazole ring with two nitrogen atoms situated at 1, 3 position fused to benzene [1] (Figure 1). Imidazole ring core structure shows biological activity against heart diseases [2].<smiles>Cn1cnc2ccccc21</smiles>

Figure 1. Structure of benzimidazole.

The first benzimidazole was introduced by Hoebrecker in 1872, who obtained 2, 5(or $2,6)$ dimethyl benzimidazole $(6,7)$ by the reduction of 2-nitro 4- methyl acetanilide [3]. The development of simple, efficient, environmentally benign, and economically viable chemical processes or methodologies for widely used organic compounds is of great demand [4]. The most prominent benzimidazole is $\mathrm{N}$-ribosyl-dimethylbenzimidazole, which is an axial ligand for cobalt in vitamin B12 [5]. Substituted derivatives of benzimidazoles have found commercial application in veterinarian medicine as anthelmintic agents and diverse therapeutics [6]. Benzimidazole is a nitrogen-containing bicyclic heterocyclic compound that shows a wide range of biological activities such as antioxidant [7], antiviral [8], antifungal [9], anticancer [10], antihypertensive [11], antimicrobial [12], anti-tumor [13] and antibacterial [14] activities.

Benzimidazole is a very useful intermediate for the synthesis of pharmaceuticals and biologically active compounds. Many scientists have developed various methods for the synthesis of benzimidazoles using different catalysts such as zinc acetate [15], solid acid scolecite [16], silica boron sulfonic acid (SBSA) [17], bismuth nitrate [18], VB1 [19], zincsulfate [20], etc. 
Pomegranate shows an antioxidant activity due to the abundance of flavonoids, anthocyanins, and catechins in different parts like fruits, seeds, and peels. Its peels cover a major portion of fruit, constituting about $60 \%$ of the fruit carrying various ingredients such as calcium, sodium, potassium, phosphorus, and magnesium [21]. Several alkaloids are found in pomegranate peel, such as ellagic acid, gallic acid chlorogenic acid, cinnamic acid, protocatechuic hydroxy acid, hydroxybenzoic acid, etc. [22]. According to the literature, we observed that pomegranate peel has the ability to donate a proton; therefore, it has an acidic character.

Considering the economic and environmental point of view, now a day's more study has been focused on the synthesis of organic compounds using natural catalysts. These catalysts have advantages like easily accessible, safe, and eco-friendly nature. Herein we report the onepot synthesis of benzimidazole derivatives by the reaction of substituted aromatic aldehydes and o-phenylenediamine by using ethanol as a solvent in the presence of pomegranate peel powder (PGP) as a natural catalyst at room temperature in a short reaction time.

\section{Materials and Methods}

Chemicals were spectrochem made and used without further purification. The reaction's progress was monitored using TLC plates in 70\% n-hexane: 30\% ethyl acetate. Melting points were recorded in capillaries open at one and were uncorrected. The products were confirmed by comparing their physical constant the literature values, ${ }^{1} \mathrm{H}$ NMR, IR, mass spectral data.

\subsection{Synthesis of benzimidazoles.}

Pomegranate peel powder (PGP) (10 wt $\%$ ) was added to a mixture of aromatic aldehydes $(1 \mathrm{mmol})$ and o-phenylenediamine $(1 \mathrm{mmol})$ in ethanol solvent, and the contents were stirred for the appropriate time as mentioned in (Scheme 1, Table 1). The progress of the reaction was monitored by TLC in n-hexane: ethyl acetate (7:3). After completing the reaction, the solvent of ethanol from the reaction mixture was evaporated, and the reaction mixture was poured onto ice-cold water and filtered off. The resulting solid was further purified by recrystallization from ethanol.

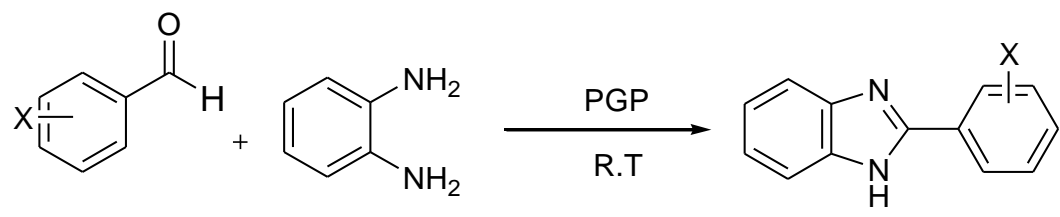

Scheme 1. Synthesis of Benzimidazoles.

2-(4-Methoxy-phenyl) benzimidazole [Entry 1] ${ }^{1} \mathrm{H}$ NMR (DMSO-d6): $\delta$ ppm $11.30(\mathrm{~s}, 1 \mathrm{H})$, $8.04(\mathrm{~d}, 2 \mathrm{H}), 7.52-7.61(\mathrm{~m}, 2 \mathrm{H}), 7.26-7.28$ (m, 2H), 7.10 (d, 2H), 3.73 (s, 3H); ESI-MS: 225.09 $(\mathrm{M}+1)^{+}$.

2-(3-nitro-phenyl) benzimidazole [Entry 4]: ${ }^{1} \mathrm{H}$ NMR (DMSO-d6): $\delta$ ppm 12.5 (s, 1H), 8.5 (s, $1 \mathrm{H}), 8.15(\mathrm{~d}, 1 \mathrm{H}), 8.25(\mathrm{~d}, 1 \mathrm{H}), 7.30(\mathrm{t}, 1 \mathrm{H}), 7.2-7.3(\mathrm{~m}, 2 \mathrm{H}), 7.22(\mathrm{t}, 2 \mathrm{H})$; ESI-MS: 240.06 $(\mathrm{M}+1)^{+}$. 
Table 1. Synthesis of benzimidazole derivatives.

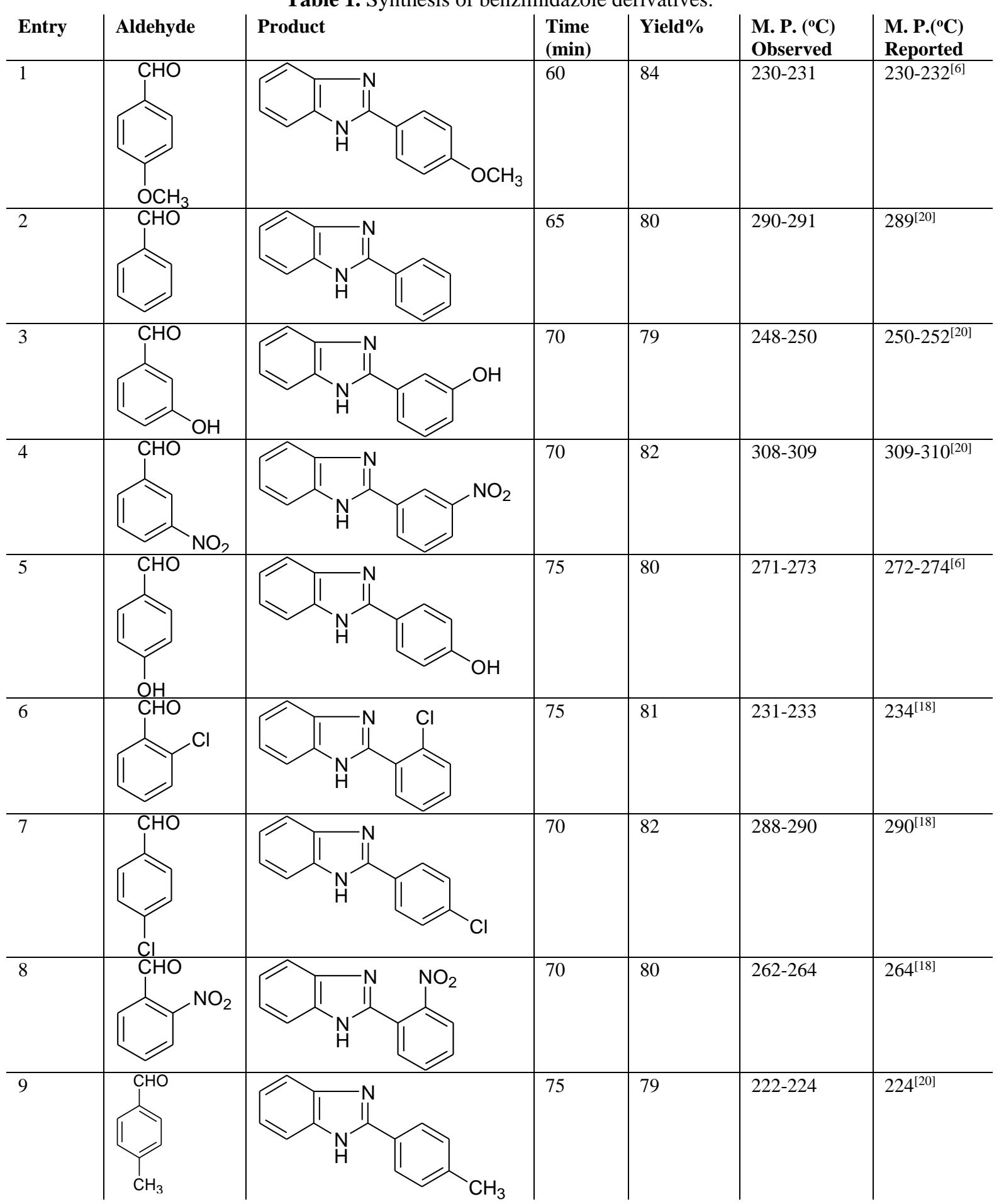

\section{Results and Discussion}

A model reaction was carried out on 4-methoxy benzaldehyde $(1 \mathrm{mmol})$ and ophenylenediamine $(1 \mathrm{mmol})$ using pomegranate peel powder (PGP) $(10 \mathrm{wt} \%)$ in ethanol solvent at room temperature (Scheme 2, Table 2).<smiles>COc1ccc(C(=O)c2cccc(-c3nc4ccccc4[nH]3)c2)cc1</smiles>

Scheme 2. Model reaction for the synthesis of benzimidazole derivatives. 
Table 2. Effect of different solvents on the synthesis of benzimidazole derivatives.

\begin{tabular}{l|c|c|c|c} 
Entry & Solvent & Time(min) & Amount of catalyst & Yield\% \\
\hline 1 & Water & 120 & 10 & 47 \\
\hline 2 & Without solvent & 180 & 10 & 32 \\
\hline 3 & Ethanol & 60 & 10 & 84
\end{tabular}

Initially, the reaction was carried out in water solvent at room temperature; but the desired product was obtained in a significantly less amount, $47 \%$. Then we carried out the same reaction without solvent and ethanol solvent at room temperature. We observed that the desired product was obtained in $32 \%$ and $84 \%$ yield, respectively. The solvent-free condition required more time $(180 \mathrm{~min})$ for the completion of the reaction as compared to water solvent (120 min) and ethanol solvent (60 min). Excellent yields were obtained in ethanol solvent in a short reaction time compared to water and without solvent (Table 2).

Later on, we investigated the effect of catalyst concentration on model condensation reaction by varying the amounts of catalyst concentration from $5,10,15,20 \mathrm{wt} \%$. We found that $10 \mathrm{wt} \%$ of the catalyst was sufficient enough to carry out the reaction (Table 3 ).

Table 3. Effect of catalyst concentration on the synthesis of benzimidazole derivatives.

\begin{tabular}{c|c|c} 
Entry & Amount of catalyst (wt \%) & Yield (\%) \\
\hline 1 & 5 & 40 \\
\hline 2 & 10 & 84 \\
\hline 3 & 15 & 80 \\
\hline 4 & 20 & 80
\end{tabular}

To get different products, various aldehydes were used, and the results are shown in Table 1 . Most of the aldehydes afforded excellent yields of over $80 \%$. The highest yield $(84 \%)$ was obtained in the case of 4-methoxy benzaldehyde as the starting material (Table 1).

\section{Conclusions}

In conclusion, we developed a green method for the synthesis of benzimidazoles by the reaction of o-phenylenediamine with different substituted aromatic aldehydes using pomegranate peel powder (PGP) as a natural heterogeneous catalyst in ethanol as a green solvent. This method's important features are short reaction time, high yield, and ease of availability of the catalyst.

\section{Funding}

This research received no external funding.

\section{Acknowledgments}

The authors are thankful to the Principal, Deogiri College, Aurangabad, for providing the necessary laboratory facilities.

\section{Conflicts of Interest}

The authors declare no conflict of interest.

\section{References}

1. Prashant, N.; Kumar, K.R. Green synthesis of benzimidazole derivatives: An overview of bulk drug synthesis. International Journal of Pharm Tech Research 2015, 8, 60-68. 
2. Lauro, F.V.; Francisco, D.C.; Marcela, R.N.; Virginia, M.A.;Elodia, G.C.; Eduardo, P.G.; Lenin, H.H.; Maria, L.R.; Regina, C.C.; Raquel, E.B. Synthesis and biological activity of two oxireno-azecin-imidazole derivatives on perfusion pressure via guanylate cyclase inhibition. Biointerface research in applied chemistry 2018, 8, 3543-3551.

3. Chawla, A.; Kaur G.; Sharma A.K. Green chemistry as a versatile technique for the synthesis of benzimidazole derivatives: review. Int. J. Pharm, Phytopharmacol. Res. 2012, 2, 148-159.

4. Rithe, S.R.; Jagtap, R.S.; Ubarhande, S.S. One pot synthesis of substituted benzimidazole derivatives and their characterization. RASAYAN, J chem. 2015, 8, 213-217.

5. Walia, R.; Hedaitullah, M.; Naaz, S.F.; Iqbal, K.; Lamba, H.S. Benzimidazole derivatives-An overview. International journal of research in pharmacy and chemistry 2011, 1 .

6. Nannapaneni, D.T.; Gupta, A.V.; Reddy, M.I.; Sarva, R.C.V. Synthesis Characterization, and biological evaluation of benzimidazole derivatives as potential anxiolytics. J Young Pharm 2010, 2, 273-279, https://doi.org/10.4103/0975-1483.66809.

7. Sawant, R.; Kawade, D. Synthesis and biological evaluation of some novel 2-phenyl benzimidazole-1acetamide derivatives as potensial anthelmintic agent. Acta. Pharm 2011, 61, 353-361, https://doi.org/10.2478/v10007-011-0029-z.

8. Shirkhania, P.; Seifourniab, H.; Mirzanzadeh, E.; Rekavandib, M.; Saeid, M.S.; Abadb, A.S.; Maikehib, Z.; Tuyehdarvary, S.R. Tribromo melamine (TBM) as an efficient and inexpensive catalyst for the one pot synthesis of benzimidazole and benzoxazole derivatives. Asian journal of green chemistry 2018, 2, 160-170.

9. Rajabi, F.; De, S.; Luque, R. An efficient synthesis of benzimidazole derivatives using SBA-15 supported Cobalt Nanocatalyst. Catal. Lett. 2015, 145, 1566-1570, https://doi.org/10.1007/s10562-015-1546-z.

10. Hadole, C.D.; Rajput, J.D.; Bendre, R.S. Concise on some biologically importantS 2-substituted benzimidazole derivatives. Organic Chem. Curr. Res. 2018, 7, https://doi.org/10.4172/2161-0401.1000195.

11. Srestha, N.; Banerjee, J.; Srivastava, S. A review on chemistry and biological significance of benzimidazole nucleus. IOSR journal of pharmacy 2014, 4, 28-41, https://doi.org/10.9790/3013-0401201028041.

12. Sontakke, V.A.; Ghosh, S.; Pravin, P.; Lawande, B.A.; Chopade, Shinde V.S. A simple, efficient synthesis of 2-aryl benzimidazoles using silica supported periodic acid catalyst and evaluation of anticancer activity. ISRN Organic chemistry 2013, https://doi.org/10.1155/2013/453682.

13. Kathirvelan, D.; Yuvaraj, P.; Babu, K.; Arasamputtu, S.N.; Boreddy, Reddy, S.R. A green synthesis of benzimidazole. Indian journal of chemistry 2013, 52B, 1152-1156.

14. Lauro, F.V.; Francisco, D.C.; Maria, L.R.; Marcela, R.N.; Virginia, M. A.M.; Alejandara, G.E.; Regina, C.C. Experimental and theroticale valuation of two indol- steroid- cyclobuta-imidazole derivatives as antibacterial drugs. Biointerface research in applied chemistry 2019, 9, 4405-4415, https://doi.org/10.33263/BRIAC95.405415.

15. Patil, V.D.; Gole, M.; Mhatre, S.; Jaiswal, A. A mild and efficient synthesis of benzimidazole by using zinc acetate under solvent free condition. Der Chemica Sinica 2010, 1, 125-129.

16. Gadekar, L.S.; Arbad, B.R.; Lande, M.K. Eco-friendly synthesis of benzimidazole derivatives using solid acid scolecite catalyst. Chinese chemical letters 2010, 21, 1053-1056, https://doi.org/10.1016/j.cclet.2010.03.038.

17. Sajjadifar, S.; Mirshokraie, S.A.; Javaherneshan, N.; Louie, O. SBSA as a new and efficient catalyst for the one-pot green synthesis of benzimidazole derivatives at room temperature. American journal of organic chemistry, 2012, 2, 1-6, https://doi.org/10.5923/j.ajoc.20120202.01.

18. Mahire, V.N.; Mahulikar, P.P. Facile one pot clean synthesis of benzimidazole motifs: Exploration on bismuth nitrate accelerated subtle catalysis. Chinese chemical letters 2015, 26, 983-987, https://doi.org/10.1016/j.cclet.2015.04.012.

19. Lie, M.; Ma, L.; Hu, L. One-pot synthesis of 1H-Benzimidazole derivatives using thiamine hydrochloride as a reusable organocatalyst. Syn. Comm. 2012, 42,2981-2993, https://doi.org/10.1080/00397911.2011.573610.

20. Patil, D.D. A mild and efficient synthesis of benzimidazole by using zinc sulphate solvent free condition. $U J P B, 2013,1,22-23$

21. Arshad, H.R.; Mohamed, A.A.; Sale, A.A. Active constituent of pomegranates (punica granatum) as potensial candidates in the managements of health through modulation of biological activities. Pharmacognosy Journal 2017, 9, 689-695, http://dx.doi.org/10.5530/pj.2017.5.109.

22. Shaygannia, E.; Bahmani, M.; Zamanzad, B.; Kopaie, M.R. A review study on punica granatum L. Journal of evidence-based complementary and alternative medicine 2016, 21, 221-227, https://doi.org/10.1177/2156587215598039.

23. Pratheesh, V.B.; Benny, N.; Sujatha, C.H. Isolation, stabilization and characterization of xanthophylls from marigold flower-Tagetes erecta-L. Modern applied science 2009, 3, https://doi.org/10.5539/mas.v3n2p19. 